\title{
Errata
}

We regret that there were a number of errors in some recently published papers. The corrections appear below and we request that our readers take them into account.

Vol. 8, No 4, 1983, pp. 363-372

\section{Urinary excretion kinetics of intact quinidine and 3-OH-quinidine after oral administration of a single oral dose of quinidine gluconate in the fasting and non-fasting state}

JEAN-MAURICE ST-ONGE *, GÉRARD SIROIS * and MARC-ANDRÉ GAGNON **

* Faculté de Pharmacie, Université de Montréal, Québec, Canada

** Service de Recherche du Centre Hospitalier L.H.-Lafontaine, Montréal, Québec, Canada

The following corrections should be made in sections of Data analysis (p. 365), Results (p. 366) and Discussion (p. 368) : One should read

$\left(\Delta D_{u} / \Delta t\right)_{\max }$ instead of $\left(\Delta D_{\mathrm{u} 8} D t\right)_{\max }$,

$\left(\Delta D_{\mathrm{u}} / \Delta \mathrm{t}\right) / \mathrm{C}_{\mathrm{s}}$ instead of $\left(\Delta \mathrm{D}_{\mathrm{uB}} \mathrm{Dt}\right) \mathrm{C}_{\mathrm{s}}$,

$F k_{e}$ instead of $F K_{e}$, and

$\left(\Delta \mathrm{DM}_{\mathrm{u}} / \Delta \mathrm{T}\right)_{\max }$ instead of $\left(\Delta \mathrm{DM} \mathrm{u}_{\mathrm{u} 8} \mathrm{Dt}\right)_{\max }$.

The time of occurence of $\left(\Delta D M_{u} / \Delta t\right)_{\max }=T^{\prime}{ }_{\max }$.

The apparent half-life of the metabolite $=t^{\prime} \frac{1}{2}$.

The parameters in Table II should be read, from top to bottom, as follows: $\left(\Delta D_{u} / \Delta t\right)_{\max }, T_{\max }, t^{1}, T_{\max }^{\prime}, t^{\prime}$. $^{\prime}$ Line 11 in the last paragraph should read : an additional $76 \%$ of non-measured metabolites.

Vol. 9, No 1, 1984, pp. 41-55

\section{The metabolic fate of ${ }^{2} \mathrm{H}$-labelled propafenone in man}

\section{H.G. HEGE*, M. HOLLMANN**, S. KAUMEIER**, H. LIETZ*}

Biochemical * and Human Pharmacology Department **,

Knoll AG, Unternehmensbereich Pharma der BASF Aktiengesellschaft, Ludwigshafen/Rhein, GFR.

This paper was received not in November 1983 as stated but in November 1982.

Figure 8 and 9 are interchanged and also the legends of these figures are incorrect and should be replaced by the following:

Fig. 8: DCI-mass spectrum of Fraction 1 of the bile extract

Fig. 9: DCI-mass spectrum of Fraction 2 of the bile extract. 